\title{
Editorial dossiê "Oralidade e garantias processuais penais": de qual oralidade podemos falar?
}

\author{
Editorial dossier "Orality and criminal procedure guarantees": \\ what orality can we speak?
}

\section{Flaviane de Magalhães Barros Bolzan de Morais ${ }^{1}$}

Doutora em Direito pela PUC-Minas

Professora da PUC-Minas e da UFOP - Belo Horizonte e Ouro Preto/MG Bolsista produtividade CNPq. Editora-associada da RBDPP neste dossiê

barros.flaviane@gmail.com

lattes.cnpq.br/1159840059123495

orcid.org/0000-0002-2377-6026

Resumo: O presente editorial desenvolve uma anál ise da compreensão da oralidade a partir das garantias fundamentais, vinculando-a como uma técnica que pode permitir a ampliação do contraditório, da ampla argumentação, da fundamentação da decisão e da imparcialidade do juiz. Buscou-se dialogar criticamente com a conformação da oralidade na teoria do processo brasileira e sua forte vinculação com a tradição inquisitorial. O debate com os autores do dossiê permite discutir outras possibilidades de compreensão da oralidade e as experiências nas reformas processuais chilena e argentina.

Palavras-chave: editorial; dossiê; oral idade; garantias processuais penais.

ABSTRACT: This editorial devel ops an analysis of the understanding of oral ity from the fundamentalguarantees. The oralityis a technique that allows the amplification of the full defense and adversary proceedings. The editorial proposes a critical dialogue with the conformation of orality in the theory of the Brazilian

1 Doutora e Mestre em Direito pela PUC Minas. Pós-doutora (CAPES) junto a Università degli studi di Roma TRE. Pesquisadora Visitante da Università degli studi di Roma TRE e Università di Firenze (Centro di Studio per la Storia del Pensiero Giuridico Moderno). Professora da PUC Minas. Professora da UFOP. Pesquisadora de Produtividade do CNPq. Advogada, Consultora jurídica. 
process and its strong connection with the inquisitorial tradition. The debate with the authors of the dossier allows us to discuss other possibilities for understanding orality and experiences in Chilean and Argentine procedural reforms.

KEY-WORDS: editorial; dossier; oral ity; criminal procedure guarantees.

Inicialmente, gostaria de agradecer aos editores da Revista Brasileira de Direito Processual Penal pelo convite. Participar como Editora-associada do Dossiê que discute a oralidade e seu vínculo com as garantais processuais penais foi muito gratificante.

Devo ressaltar os méritos desse dossiê decorrem do trabalho primoroso de coordenação e direção da editoria-chefe da Revista, do apoio de todos os pareceristas que colaboraram para a avaliação cega e realizaram debates muito interessantes com os autores dos textos, e dos autores desse dossiê que contribuíram com seus estudos e reflexões sobre o tema. A mim coube a melhor parte que foi ler e contemplar os textos aprovados e buscar dialogar com eles.

A oralidade não é uma "moda" nova ou uma tendência do direito processual penal que apareceu há pouco no Brasil. Ela é velha conhecida de todos que estudam direito processual penal. Nós, brasileiros que temos o direito processual fortemente influenciado pela tradição romano-canônica, denominação aqui apropriada da obra de Ovídio Baptista ${ }^{2}$, já ouvíamos há muito falar de oralidade. Calamandrei ${ }^{3}$ ressalta que esse debate seja na Itália quanto na Alemanha data do início do século.

O tema foi retomado no movimento da reforma parcial dos Códigos de processo brasileiros (civil e penal) após o processo de redemocratização com o fim da ditadura civil militar e a nossa "nova" agora velha ordem constitucional.

Os debates nessa fase dividiam a oralidade em quatro dimensões para explicar a operacionalização do denominado princípio da

2 Sobre isso, ver: BAPTISTA DA SILVA, Ovidio. Jurisdição e execução na tradição romano-canônica. São Paulo: Revista dos Tribunais, 1996.

3 Sobre isso, ver: CALAMANDREI, Piero. Opere giuridiche. Vol. I. Problemi generali del diritto e del processo. Napoli: Morano, 1965. 
oralidade. Seu objetivo precípuo era justificar a introdução no sistema processual da audiência de instrução e julgamento, que simbolizava um grande avanço em termos de celeridade para os idealizadores das reformas parciais. Assim, a oralidade era dimensionada a partir da identidade física do juiz, da imediação, da concentração de atos e da proibição de recorrer das decisões interlocutórias em audiência. Certo é que essa oralidade do movimento de reforma parcial dos códigos de processo brasileiros iniciado nos anos 90, e que durou até o final da primeira década do século XXI, não é a oralidade que os autores do presente dossiê da Revista Brasileira de Direito Processual Penal estão discutindo.

O objetivo do presente dossiê era justamente buscar fomentar o debate sobre oralidade que não partisse da estruturação tradicional que se voltou exclusivamente para a proposição da audiência de instrução e julgamento como a base desse princípio nos processos jurisdicionais brasileiros e que como já se ressaltou foi a tônica da reforma parcial dos códigos de processo brasileiros.

A proposta era convergir a discussão para vincular a oralidade às garantias processuais e realizar um debate entre a viabilidade ou não de se implantar procedimentos orais em reformas processuais. Em especial, buscava-se descortinar a possibilidade de revisão da cultura inquisitória que estava impregnada em legislações processuais penais, em especial, da América Latina, e se é possível em um processo de reforma macroestrutural efetivo, viabilizar a oralidade para o processo penal a partir de uma verdadeira dinâmica acusatória.

Nesse sentido, dois dos artigos publicados representam de forma clara a importância do tema oralidade para as reformas processuais da América Latina. Os artigos auxiliam a comunidade acadêmica científica brasileira a entender os passos de nossos vizinhos (Argentina e Chile, no caso desse dossiê) nas suas reformas processuais. Se por um lado, a reforma do sistema processual penal chileno já guarda uma experiência de mais de 10 anos de juízo oral, a reforma do código da nação argentina data de 2014.

Os dois artigos apresentados representam, além de toda a sua importância acadêmica, a aproximação feita pela academia processual penal brasileira com as experiências de reformas processuais penais da América Latina, que contribui sobremaneira para o fomento de pesqui- 
sas comparadas. A colaboração de membros do CEJA com artigos para esse dossiê é além de uma grande honra para a nossa Revista, uma demonstração de que os esforços em aproximar os estudos e debates nas Américas está sendo efetivo.

A análise feita pelo autor do artigo "La renuncia a las garantías del juicio oral por medio del procedimiento abreviado", Cristián Riego, além de discutir oralidade, ajuda a compreende o desafio que foi no Chile a reforma da legislação processual penal de inquisitória em essência para um modelo acusatório de matriz adversarial. A reforma chilena do juízo oral não significou a simples previsão de concentração do ato de instrução em audiência e do julgamento imediato, e em sequência. Ou seja, não introduzir uma "AIJ" como foi feito no Brasil. Foi uma mudança de mentalidade, de cultura. Foi necessário colocar cada sujeito processual em seu devido lugar, como há muito Jacinto Nelson Miranda Coutinho ${ }^{4}$ já tem dito sobre a questão no Brasil. Assim, o autor do artigo ressalta a mudança da perspectiva da apresentação da prova e da cognição do juiz sobre os elementos de prova por meio do exame e contra-exame. As partes - acusação e defesa - se apresentam no juízo oral como as protagonistas do debate, em que confrontam suas versões em um diálogo.

Creio que a experiência chilena nos demonstra que a mera adaptação de alguns termos como a introdução de uma característica da oralidade como a da nossa "AIJ" não é a suficiente e tampouco adequada para quem pretende a adoção de um sistema adversarial. A necessidade de uma mudança de mentalidade e de cultura se faz real. E ela não ocorre apenas incluindo a concentração de atos em audiência, a imediação do juiz junto aos elementos de prova, a sua identidade física e a proibição de recorrer das decisões tomadas em audiência.

A oralidade precisa ser vista como uma boa técnica processual quando vinculada a uma estrutura processual baseada no sistema acusatório, construída de forma a impor a efetividade dos princípios constitucionais. Essa é a minha perspectiva que creio dialoga com todos os textos publicados nesse dossiê, e que pretendo desenvolve-la neste editorial.

4 COUTINHO, Jacinto Nelson de Miranda. Sistema Acusatório - Cada parte no lugar constitucionalmente demarcado. Revista de informação legislativa, Brasília, v. 46, nº 183, p. 103-115, jul./set. 2009. 
Como ressaltado por Riego, na reforma processual chilena adotou-se o juízo oral como base para a cognição e construção da decisão em processo penal que se pretende a aplicação de pena, no âmbito criminal. Seu objetivo precípuo era além de reforçar o caráter republicano, e democrático (incluo eu essa observação), do processo penal como base de um sistema de justiça, a superação da mentalidade inquisitória do sistema anterior por meio de uma estrutural procedimental que deixa clara a separação entre a atuação judicial, que julga com imparcialidade, da acusação; a efetivação de forma plena e integral da garantia da ampla defesa do acusado; a formação da cognição pelos julgadores baseada exclusivamente nas provas apresentadas ao juízo oral de forma pública e inédita aos julgadores.

Gostaria de deixar isso mais claro, pois é de suma importância essa compreensão para nos brasileiros. A imparcialidade somente será verdadeiramente caracterizada em uma estrutura processual que assegure que o juiz, ou melhor, os juízes, pois no Chile a decisão do juízo oral em primeira instância é colegiada, apreendam e formulem compreensões sobre elementos de prova que são inéditos. Logo, eles não podem ter participado de nenhuma decisão sobre aquele caso penal antes, seja ela uma decisão cautelar, como é o caso da decisão de prisão preventiva, ou de análise da viabilidade de acusação, como é o caso da decisão que recebe a denúncia. Eis aí uma estrutura processual que prioriza a garantia do processo penal constitucional.

A discussão sobre qual o modelo de justiça criminal que buscamos depende também, como no Chile, de uma escolha política. Política aqui não significa politicagem, e sim uma compreensão que leve em conta as escolhas políticas do nosso texto constitucional.

O texto de Riego foi muito feliz em ressaltar os dilemas atuais da reforma parcial ocorrida no Chile que permite um acordo para que o acusado abra mão do juízo oral. A lei foi aprovada a partir de um diagnóstico sobre a denominada "Criminalidade comum" formada por condutas vinculadas aos delitos patrimoniais, que são, segundo as pesquisas chilenas, os responsáveis pelos maiores impactos na política de segurança pública. Dentre as reformas no sistema de justiça que visavam a melhorar a persecução penal desse tipo específico de criminalidade estava a ampliação do espectro da negociação. 
A grande crítica do autor à reforma efetivada em 2016 é justamente a perda da integridade do sistema de justiça penal chilena com a introdução de um modelo negocial que se afasta na proposta original chilena que adotou o sistema acusatório, mas não introduziu a cultura do plea bargaining norte-americano. Logo, o Ministério Público chileno como órgão de acusação não tinha a possibilidade de agir discricionariamente, decidindo por critérios de oportunidade se oferecia um acordo ou não, quando o acusado poderia optar pelo processo abreviado e por consequência abrir mão do juízo oral.

Como disse, a lógica da negociação abarca uma discussão importante sobre como nossa carta política pensa o sistema de justiça criminal. Certo é que a nossa Constituição não permite negociações em qualquer medida, por meio de uma lógica processual neoliberal. Se ela tivesse adotado o modelo político eficienticista não teríamos no art. $5^{\circ}$ da Constituição um núcleo de garantias processuais penais.

Assim, a discussão atual chilena sobre a reforma do seu Código se parece em muito com o debate que precisamos de forma séria enfrentar no Brasil, em especial quando a negociação ocorre em um país com uma forte cultura encarceradora. O grande risco é que, próximo à preocupação do autor quando analisa a reforma chilena, com o investigado preso é muito mais fácil negociar para ele abrir mão de direitos e ter benefícios na redução da pena privativa de liberdade.

Creio importante essa análise a partir do dossiê apresentado, pois vincula-se a alguns temas centrais da discussão jurídico teórica sobre o processo penal como o debate "eficiência versus efetividade", "garantias processuais e reforma do sistema de justiça" e "cultura inquisitória e reforma processual”.

Certamente, a necessidade de se discutir de forma profunda a mudança de cultura é algo afeito a toda a discussão de reforma. No artigo subscrito por Postigo e Podestá (em A oralidade no novo Código de Processo Penal da Nação Argentina), os autores se preocupam justamente com a viabilidade de uma mudança cultural que permita a oralidade se integrar de forma plena à estrutura processual penal e a resistência dos atuais aplicadores da norma processual a uma mudança de paradigma.

Em específico, os autores do artigo ressaltam a grande preocupação com a proposta de conciliar duas culturas diferentes: oralidade e 
escrituração, em especial, em um sistema de justiça que tem de forma arraigada práticas inquisitoriais. O debate sobre oralidade e escrituração está diretamente relacionado à discussão mais profunda das diferenças entre um sistema de justiça penal que está vinculado à tradição romano canônica e o sistema adversarial de raiz anglo-saxônica.

Creio que não podemos furtar a essa discussão, em especial, no atual ponto em que se encontra a reforma macroestrutural do processo penal brasileiro. A única forma de tornar a oralidade uma característica inerente ao processo penal, é não a vinculando a um mero instrumento para viabilizar a celeridade e eficiência, mas passando a reconhecê-la como uma técnica de efetivação e maximização das garantias processuais. É desvincular o processo penal da cultura da escrituração, que esta fortemente vinculada à necessidade de se manipular os autos do processo.

A reforma parcial de 2008 no Brasil buscou implantar outras formas de escrituração, como o registro audiovisual dos atos da audiência, mas percebe-se que essa estratégia não melhorou em nada a oralidade e muito menos surtiu o efeito mais importante que é a vinculação da oralidade como metodologia para concretização do princípio acusatório vinculado a uma cultura adversarial.

Certamente, esse editorial não permite que eu busque verticalizar a presente análise, mas pode servir de mote para que os pesquisadores de processo penal, leitores da Revista Brasileira de Direito Processual Penal, aprofundem suas pesquisas e análise sobre o tema. Mas mesmo arriscando não conseguir chegar em todas as implicações que eu gostaria sobre o tema, vou arriscar pois creio que a RBDPP é um importante veiculo de divulgação e reunião de pessoas que se preocupam com o aprimoramento do direito processual penal.

Nossa cultura de escrituração, que já foi há muito reconhecida por Taruffo ${ }^{5}$, tem forte vinculação com a existência dos autos processuais, que são controlados e regidos pelo Poder Judiciário. Uma das estratégias que se percebe para forçar a mudança da mentalidade dos julgadores na reforma chilena é a ausência dos autos, como um modelo

5 Sobre isso, ver: TARUFFO, Michele. Sui confini -Scritti sulla giustizia civile. Bologna: Il Mulino, 2002. 
de documentação não só da sequência de atos do processo, mas como engrenagem mestre da formação da cognição. Não é à toa que até hoje paira sobre os inconscientes dos aplicadores a máxima: "o que não está nos autos não está no mundo".

No juízo oral chileno os juízes não têm autos para serem manipulados, no qual se encarta todo o conjunto probatório por meio da sua reprodução escrita. O controle, a guarda e a coordenação das informações e dos elementos de prova são de exclusiva responsabilidade do órgão de acusação.

Mesmo quando se reformou a legislação brasileira, buscando modernizá-la seja pelo meio eletrônico seja por meios audiovisuais, não se mudou a lógica do pensar e do agir de todos, pois as partes também atuam sempre peticionando, ou seja, por escrito.

Aliado ao controle judicial do registro dos autos, deve-se ainda discutir a oralidade que foi absorvida pela tradição romano canônica, daquela própria da tradição adversarial. Mesmo quando se afirma que no juízo oral as provas devem ser apresentadas de forma inédita aos julgadores, não se pode deixar olvidar que é necessário mudar a lógica de como se apreende as informações que serão apresentadas em juízo. A dinâmica dialética do exame e contra-exame em debates orais no momento de apresentação do conjunto de elementos de prova exige uma inércia dos julgadores. Nesse momento, a regência está com as partes, os julgadores devem apenas presidir o ato e verificar o respeito aos direitos das testemunhas, vítimas, peritos e acusados. O pressuposto da atuação da acusação e da defesa é a lealdade processual, o fair play. Logo, o papel dos juízes não está em verificar a conformidade da atuação das partes, mas em apreender elementos para formação da decisão que são apresentados pelas partes em contraditório por meio do confronto entre a tese da acusação e as objeções da defesa. Não deve se ater a elementos informativos, pois eles não estão em sua posse, já que se supera o uso dos autos. Sua atenção deve estar voltada às pessoas que vão ser apresentadas como testemunhas, vítimas ou acusados, aos esclarecimentos técnicos dos peritos e às outras formas de apresentação dos elementos probatórios colhidos pela acusação ou defesa.

Certamente, se não operar uma verdadeira mudança na compreensão da oralidade no Brasil quanto à referência ao processo de co- 
nhecimento em que se imputa uma conduta e discute-se a culpabilidade, a oralidade das demais fases do processo será ainda mais difícil de ser incorporada. Vê-se isso quando se compara a audiência de custodia prevista na Resolução do CNJ e a audiência presidida pelo juiz das garantias chileno. O caso analisado do Código da Nação Argentina revela a necessidade de uma mudança estrutural no procedimento para incluir a oralidade como opção política para melhoria do sistema de justiça e por consequência a sua inclusão como um princípio base do processo. A oralidade como uma técnica permite operacionalizar o sistema acusatório adversarial, o contraditório, a ampla defesa, a imparcialidade e a fundamentação da decisão.

Logo, seja como princípio político ou como técnica operacionalizadora, a oralidade é um importante instituto para viabilizar as garantias do processo. E é por isso que ela dialoga fortemente com o sistema processual penal brasileiro definido a partir da Constituição. Por isso, a discussão apresentada no artigo de Minagé (em Contraditório público e oral como garantidor de um processo penal democrático constitucional) para a Revista se mostra absolutamente relevante, já que temos condições constitucionais de pensar a oralidade como garantia advinda ou conjugada com a noção de contraditório.

Certo que não é uma noção de contraditório como simples ação e reação, mas um contraditório revisado a partir das proposições fazzalarianas como ressaltado pelo autor, e que tem sido base para pesquisa de vários e importantes processualistas que reconhecem os limites da proposição relacionista ${ }^{6}$ e os impactos da adoção de tal teoria do processo como limite à própria concretização do processo constitucional.

Como propõe Minagé, um processo em contraditório precisa se pautar pela oralidade e pela publicidade de seus atos, permitindo que todos, não só o juiz, conheçam os elementos de prova, e que todos conheçam os fundamentos da decisão judicial.

6 Ver: NEGRI, Daniele; PIFFERI, Michele. Diritti individuali e Processo Penale nell'Italia Republicana. Ferrara: Guiffrè, 2010; BARROS, Flaviane de Magalhães. O modelo constitucional de processo e o processo penal: a necessidade de uma interpretação das reformas a partir da Constituição. In: CATTONI DE OLIVEIRA, Marcelo Andrade; MACHADO, F.D.A. (Orgs.). Constituição e Processo: a contribuição do processo ao constitucionalismo 
Eu estou a ressaltar o todos, como provocação, pois é preciso que o processo penal se aproxime dos verdadeiros afetados pela decisão, que são o acusado e a vítima. E eles, em especial, no nosso processo penal seletivo, não têm em sua maioria possibilidade de compreender e acessar o que ocorre no processo.

E nesse sentido a contribuição de Carvalho (em A oralidade no processo penal a partir da noção de compreensão cênica) com a noção cênica do processo, desenvolvida a partir dos marcos de Lorenzer e Hassemer, também contribui para discutir e conciliar o contraditório pleno com a oralidade, o princípio acusatório com a oralidade.

É necessário discutirmos em um debate verdadeiramente cientifico, mesmo que as teses tenham marcos teóricos distintos, todas elas buscam um objetivo comum, que une a todos: viabilizar o processo penal como uma metodologia de garantia.

Assim, buscar compreender como os julgadores decidem, o uso de disfarces para encobrir o pré-julgamento ou mesmo a necessidade de superação do solipsismo é fundamental para aprimorarmos cada dia mais o debate que deve chegar até os setores implicados nessa discussão, seja o legislador que pretende a reforma da norma processual, sejam os operadores do direito que atuam na sua aplicação, como juízes, promotores, defensores, delegados e auxiliares da justiça.

Permitir que o direito como ciência utilize de outras bases cientificas como a psicologia e psicanálise para discutir o processo cognitivo de formação de decisões pelas pessoas é um passo importante para melhorarmos ainda mais esse debate, e no artigo de Carvalho essa proposição se apresenta pela análise das heurísticas ou dos vieses cognitivos.

A proposta de pensar cenicamente o processo penal parece-me uma interessante forma de discutirmos inclusive como as pessoas (afetados, aplicadores e comunidade) podem acessar a linguagem do direito e compreender melhor a questão penal, humanizando a questão, sem naturalizá-la.

Para mim, a oralidade tem um duplo aspecto: político, pois é preciso que todos entendam as razões pelas quais no nosso projeto poli-

democrático brasileiro. Belo Horizonte: Del Rey, 2009; LOPES JR., Aury. Fundamentos do Processo Penal. São Paulo: Saraiva, 2017. 
tico constitucional se fez uma opção pelo respeito às garantais processuais. Para lembrarmos que nossa Constituição tem um projeto político e é produto de um processo histórico como assevera Catttoni de Oliveira ${ }^{7}$. Para que não se opere o esquecimento das consequências de se deixar de lado as garantias processuais para o conjunto das liberdades, públicas e individuais. Logo, o sistema de justiça deve ser mais "acessível” às pessoas que se comunicam com ele, não é correto que ele se feche em uma linguagem ou pior em texto e autos herméticos à maioria da população brasileira, em especial, àquela que Souza $^{8}$ denominou de a "ralé brasileira”, ou seja, o sub-cidadão que está à margem do estado de direito, mas é "cliente" do sistema de justiça criminal.

O segundo aspecto da oralidade é jurídico constitucional. A oralidade deve se alinhar aos princípios constitucionais de processo e a uma noção de processo que se adeque à proposta constitucional. Nesse sentido, venho trabalhando com duas categorias teóricas que entendo serem importantes para matizar o debate. Uma delas é constitutiva na minha origem acadêmica: a compreensão do processo como procedimento em contraditório, em uma leitura fazzalariana apreendida a partir de Gonçalves ${ }^{9}$. A segunda categoria é a noção de modelo constitucional de processo, desenvolvida inicialmente por Andolina e Vignera ${ }^{10}$. Se a Constituição define uma base principiológica para o processo, ela é formada pelo contraditório, ampla argumentação, imparcialidade e fundamentação da decisão. E no que se refere ao processo penal, agrega-se nesse microssistema constitucional, o princípio da presunção de ino-

7 CATTONI DE OLIVEIRA, Marcelo Andrade. Democracia sem espera e processo de constitucionalização - Uma crítica aos discursos oficiais sobre a chamada "transição política brasileira". In: CATTONI DE OLIVEIRA, Marcelo Andrade; MACHADO, F.D.A. (Orgs.). Constituição e Processo: a contribuição do processo ao constitucionalismo democrático brasileiro. Belo Horizonte: Del Rey, 2009. p. 365- 399.

8 Sobre isso, ver: SOUZA, Jessé. A invisibilidade da desigualdade brasileira. Belo Horizonte: Editora UFMG, 2006.

9 Sobre isso, ver: GONÇALVES, Aroldo Plínio. Técnica processual e teoria do processo. $2^{\text {a }}$ tiragem. Rio de Janeiro: Aide, 1992.

10 Sobre isso, ver: ANDOLINA, Italo; VIGNERA, Giuseppe. I fondamenti constituzionali della giustizia civile: il modello constituzionale del processo civile italiano. 2. ed. Torino: Giappichelli, 1997. 
cência e o princípio acusatório. Logo, a oralidade como foi definida em vários dos artigos desse dossiê é claramente vinculada ao contraditório.

A oralidade pode, como técnica ou mesmo agregada à noção de princípio, ser um importante ganho para ordem constitucional democrática, tendo em vista justamente a sua capilaridade em permitir que os princípios do modelo constitucional de processo possam ser aplicados de forma plena e integral. Estruturando-se o processo por meio da oralidade, inserindo-a em todas as fases processuais, incluindo as decisões cautelares na fase preliminar, os recursos às instâncias do duplo grau de jurisdição e atos da fase de execução penal, teremos maior efetividade do contraditório, visto como espaço procedimentalizado para construção participada da decisão, e da ampla argumentação, já que com o debate dialético e a produção de prova por meio de exame ou contra-exame em audiência privilegia-se as partes como protagonistas da argumentação processual. O juiz ou os julgadores ficam em um lugar privilegiado de aqueles que proferem a decisão construindo uma síntese do debate, definida pela prevalência da argumentação sustentada pelo conjunto de provas apresentados e a qualidade dos fundamentos jurídicos invocados por cada um dos atores. E, por consequência, a oralidade implicará diretamente na efetividade do princípio da imparcialidade e na adequada fundamentação da decisão.

Sem sombra de dúvida um processo penal que privilegia a oralidade permitiria concretizar o princípio acusatório e auxiliaria na superação da cultura inquisitória da nossa tradição processual.

E assim, esse editorial tenta fechar um ciclo de diálogo com o artigo de Sampaio e Melo (em Cultura inquisitória e as falsas oralidades). Certa é a sua conclusão sobre a baixa intensidade da oralidade no Brasil, em especial, aquela que foi inserida pelas reformas parciais iniciadas na década de 90 ou a existente desde a formulação original do nosso Código de Processo Penal. São exemplos de uma falsa oralidade, pois ela não está a cargo do princípio acusatório e de uma melhor qualificação da decisão pela verdadeira imediação decorrente do conhecimento integral e inédito dos julgadores.

Creio que a leitura dos cinco artigos do dossiê permite fechar em um círculo argumentativo uma noção importante da oralidade. E fica claro como ele se fecha quando os autores demonstraram que o que se tem no Brasil é uma falsa oralidade ou uma oralidade de baixa inten- 
sidade, ou seja, lugar próximo ao que eu pessoalmente iniciei a minha análise nesse editorial.

A adoção da oralidade em sentido forte somente é possível com a concretização do princípio acusatório e a assunção por parte dos sujeitos processuais de seu lugar constitucional. Mas também pela superação do nosso incônscio inquisitório, para usar a expressão formulada pelos processualistas italianos em um encontro acadêmico em Milão ${ }^{11}$, ou mentalidade inquisitória como tem sido discutido em encontros brasileiros assim intitulados.

Sem dúvida a oralidade em sentido fraco como é a nossa, mais do que indicar um caminho no sentido da maximização do princípio acusatório no Brasil, significou a consolidação de um processo penal fundado na supervalorização do papel do juiz e na interpenetração da função de julgar e acusar. É uma bela estratégia de encobrimento que esse dossiê tenta em seus limites desvelar e denunciar, objetivando um debate verdadeiro sobre os propósitos da nossa reforma processual macroestrutural que não se preocupou em buscar solucionar esse simulacro de processo que não permite a afirmação das garantais constitucionais e tem sido usado simbolicamente para outros fins que não os legítimos e constitucionalmente admitidos.

Assim, com essa feliz constatação que os textos do dossiê se fecham em um círculo argumentativo e com a forte convicção que os trabalhos aprovados contribuem em muito para o debate sobre o tema e para o engrandecimento da pesquisa científica brasileira, convoco a todos os leitores da Revista Brasileira de Direito Processual Penal para mais esse dossiê.

Belo Horizonte, 07 de setembro de 2017.

\section{REFERENCIAS BIBLIOGRÁFICAS}

ANDOLINA, Italo; VIGNERA, Giuseppe. I fondamenti constituzionali della giustizia civile: il modello constituzionale del processo civile italiano. 2. ed. Torino: Giappichelli, 1997.

11 Sobre isso: GARLATI, Loredana. L'inconscio inquisitório. L'eredità del Codice Rocco nella cultura processualpenalistica italiana. Milano: Giuffrè, 2010. 
BAPTISTA DA SILVA, Ovidio. Jurisdição e execução na tradição romano-canônica. São Paulo: Revista dos Tribunais, 1996.

BARROS, Flaviane de Magalhães. O modelo constitucional de processo e o processo penal: a necessidade de uma interpretação das reformas a partir da Constituição. In: CATTONI DE OLIVEIRA, Marcelo Andrade; MACHADO, F.D.A. (Orgs.). Constituição e Processo: a contribuição do processo ao constitucionalismo democrático brasileiro. Belo Horizonte: Del Rey, 2009.

CALAMANDREI, Piero. Opere giuridiche. Vol. I. Problemi generali del diritto e del processo. Napoli: Morano, 1965.

CATTONI DE OLIVEIRA, Marcelo Andrade. Democracia sem espera e processo de constitucionalização - Uma crítica aos discursos oficiais sobre a chamada “transição política brasileira”. In: CATTONI DE OLIVEIRA, Marcelo Andrade; MACHADO, F.D.A. (Orgs.). Constituição e Processo: a contribuição do processo ao constitucionalismo democrático brasileiro. Belo Horizonte: Del Rey, 2009. p. 365- 399.

COUTINHO, Jacinto Nelson de Miranda. Sistema Acusatório - Cada parte no lugar constitucionalmente demarcado. Revista de informação legislativa, Brasília, v. $46, \mathrm{n}^{\mathrm{o}} 183$, p. 103-115, jul./set. 2009.

GARLATI, Loredana. L'inconscio inquisitório. L'eredità del Codice Rocco nella cultura processualpenalistica italiana. Milano: Giuffrè, 2010.

GONÇALVES, Aroldo Plínio. Técnica processual e teoria do processo. $2^{\mathrm{a}}$ tiragem. Rio de Janeiro: Aide, 1992.

LOPES JR., Aury. Fundamentos do Processo Penal. São Paulo: Saraiva, 2017.

NEGRI, Daniele; PIFFERI, Michele. Diritti individuali e Processo Penale nell'Italia Republicana. Ferrara: Guiffrè, 2010.

SOUZA, Jessé. A invisibilidade da desigualdade brasileira. Belo Horizonte: Editora UFMG, 2006.

TARUFFO, Michele. Sui confini - Scritti sulla giustizia civile. Bologna: Il Mulino, 2002. 


\section{Informações adicionais e declarações do autor (integridade científica)}

Declaração de conflito de interesses (conflict of interest declaration): a autora confirma que não há conflitos de interesse na realização das pesquisas expostas e na redação deste editorial.

Declaração de autoria (declaration of authorship): todas e somente as pessoas que atendem os requisitos de autoria deste editorial estão listadas como autores.

Declaração de ineditismo e originalidade (declaration of originality): a autora assegura que o texto aqui publicado não foi divulgado anteriormente em outro meio e que futura republicação somente se realizará com a indicação expressa da referência desta publicação original; também atesta que não há plágio de terceiros ou autoplágio.

COMO CITAR ESTE EDITORIAL:

BARROS, Flaviane M. Editorial Dossiê "Oralidade e garantias processuais penais": de qual oralidade podemos falar? Revista Brasileira de Direito Processual Penal, Porto Alegre, vol. 3, n. 3, p. 809-823, set./dez. 2017. https://doi.org/10.22197/rbdpp.v3i3.106

\section{(c) $(1)(9)$}

Esta obra está licenciada com uma Licença Creative Commons Atribuição-NãoComercial 4.0 Internacional. 